\title{
Bone Matrix Constituents Stimulate Interleukin-1 Release from Human Blood Mononuclear Cells
}

\author{
Roberto Pacifici, Aldo Carano, * Samuel A. Santoro, ${ }^{*}$ Leonard Rifas, John J. Jeffrey, \\ J. David Malone," Ruth McCracken, and Louis V. Avioli \\ Divisions of Bone and Mineral Metabolism, Laboratory Medicine, ${ }^{\ddagger}$ and Dermatology, ${ }^{\S}$ Departments of Medicine and Pathology, \\ Washington University School of Medicine and Medical Center; Department of Pathology,* The Jewish Hospital \\ of St. Louis; and Department of Medicine and Pharmacology," St. Louis University and John Cochran \\ Veterans Administration Medical Center, St. Louis, Missouri 63110
}

\begin{abstract}
To test the hypothesis that mononuclear cells are stimulated to release interleukin 1 (IL-1) by bone fragments released in the bone microenvironment during the remodeling cycle, we have investigated the effects of bone matrix and some of its constituents on IL-1 secretion from peripheral blood mononuclear cells (PBMC). Increases in IL-1 activity were observed when either PBMC or adherent monocytes, but not lymphocytes depleted of monocytes, were co-cultured with either human or rat bone particles but not with latex particles of similar size. Co-culture of PBMC with bone particles in a transwell system where the cells were physically separated from the bone particles, or with osteoblast- or osteoclast-covered bone particles, did not stimulate IL-1 release, indicating that a physical contact between PBMC and the bone surface is required for eliciting IL-1 release. This was confirmed by the finding of a lower stimulatory effect of bone particles pretreated with etidronate, a bisphosphonate which decreases the bone binding capacity of PBMC. Constituents of bone matrix, such as collagen fragments, hydroxyproline, and, to a lesser extent, transforming growth factor- $\beta$, but not osteocalcin, $\alpha_{2}$ HS glycoprotein, fragments of either bone sialoprotein or osteopontin, and fibronectin, stimulated PBMC IL-1 release in a dose-dependent fashion. Collagen-stimulated IL-1 release was partially and specifically inhibited by a monoclonal antibody directed against the $\alpha_{2} \beta_{1}$ integrin cell surface collagen receptor. These data demonstrate that products of bone resorption, known to be chemotactic for mononuclear cells, stimulate PBMC IL-1 activity. These findings may help explain previous documentation of increased IL1 secretion by circulating monocytes obtained from patients with high turnover osteoporosis. (J. Clin. Invest. 1991. 87:221-228.). Key words: bone matrix • collagen • integrin • interleukin $1 \cdot$ mononuclear cells • osteoporosis
\end{abstract}

\section{Introduction}

Interleukin 1 (IL-1) is a family of several, closely related, low molecular weight proteins produced by many types of mam-

Address reprint requests to Dr. Pacifici, Division of Metabolism, The Jewish Hospital of St. Louis, 216 South Kingshighway, St. Louis, MO 63110.

Received for publication 29 March 1990 and in revised form $20 \mathrm{July}$ 1990.

J. Clin. Invest.

(C) The American Society for Clinical Investigation, Inc. $0021-9738 / 91 / 01 / 0221 / 08 \$ 2.00$

Volume 87, January 1991, 221-228 malian cells, including bone cells (1-3). Although best known for its ability to promote lymphocyte proliferation $(4,5)$ and for its involvement in inflammation and wound healing (6), IL-1 is also recognized for its multiple and important effects on bone. In fact, not only is IL-1 a powerful stimulator of bone resorption in vitro $(7-9)$ and in vivo $(10,11)$, but it modulates bone cell proliferation (12-15) and collagen and noncollagen bone protein synthesis $(16,17)$, and induces the secretion of other bone active cytokines from bone cells or marrow resident mononuclear cells $(18,19)$.

In previous studies (20), we reported that circulating monocytes from subjects with "high turnover" osteoporosis, a condition marked by increased bone resorption and bone formation, elaborated higher amounts of IL-1 in vitro than those from subjects with "low turnover" osteoporosis, a disorder in which bone formation is impaired. More recently, we demonstrated that women in the early menopausal period, when enhanced bone resorption causes rapid bone loss, also display increased monocyte IL-1 activity that is blocked by ovarian steroid therapy (21). Although these observations implied a causative role for IL-1 in postmenopausal bone loss, they did not offer any insight into the mechanism(s) that lead(s) to IL-1 release in states of high bone turnover.

Monocytes are often found adjacent to bone resorbing surfaces, and resorbing bone and bone peptides released in the local microenvironment during bone resorption have been shown to be chemotactic for monocytes (22-25). Among these peptides are collagen, osteocalcin, $\alpha_{2} \mathrm{HS}$ glycoprotein, and transforming growth factor- $\beta$ (TGF- $\beta$ ), ${ }^{1}$ a cytokine produced by bone cells and enclosed in the bone matrix (25) that stimulates the expression of IL-1 messenger RNA in monocytes (24). Release of bone matrix digestion products and/or osteoblast secretory products might account for the local recruitment and activation of mononuclear cells and the resulting release of IL-1. Secretion of IL-1 from intraskeletal mononuclear cells could, in turn, play a fundamental role in the regulation of bone remodeling. Similarly, the bone-sparing effect of ovarian steroids could be explained by a regulatory effect of these hormones on the capacity of mononuclear cells, or perhaps their precursors, to release IL- 1 in response to exposure to bone matrix constituents. In this study, we examined bone matrix and some of its constituents for their effects on IL-1 release from human peripheral blood mononuclear cells (PBMC). We report that adherence of PBMC to bone matrix markedly increases the secretion of IL-1 from PBMC into the culture me-

1. Abbreviations used in this paper: EHDP, 1-hydroxy-1,1-ethane diphosphate (etidronate); LAP, lipid A-associated protein; PB, polymixin $\mathrm{B}$; TGF- $\beta$, transforming growth factor- $\beta$. 
dia. The data also reveal that the increase in IL-1 activity can be induced by some, but not all, well-characterized bone matrix constituents.

\section{Methods}

Unless otherwise specified, reagents and media were from the Sigma Chemical Co., St. Louis, MO.

Mononuclear cell cultures. PBMC cultures were prepared from blood from healthy volunteers as described $(20,21)$. Briefly, freshly drawn blood was fractionated on Ficoll/Hypaque, and the PBMC were removed from the interface and washed twice with RPMI 1640 medium. The cells were resuspended in complete medium (RPMI 1640 medium supplemented with $5 \%$ [ $\mathrm{vol} / \mathrm{vol}]$ heat-inactivated fetal bovine serum [defined, Sterile Systems, Logan, UT; endotoxin, $0.038 \mathrm{ng} / \mathrm{ml}$ ]) at a concentration of $1 \times 10^{6}$ cells $/ \mathrm{ml}$, and $1-\mathrm{ml}$ aliquots incubated in $16-\mathrm{mm}$ wells of 24 -well tissue culture plates for $48 \mathrm{~h}$ at $37^{\circ} \mathrm{C}$ in a humidified atmosphere of $5 \% \mathrm{CO}_{2} / 95 \%$ air. For some experiments 1$\mathrm{ml}$ aliquots were allowed to adhere for $2 \mathrm{~h}$ at $37^{\circ} \mathrm{C}$. After incubation the nonadherent cells (enriched lymphocytes) were removed from the wells, resuspended in $1 \mathrm{ml}$ of medium and incubated for $48 \mathrm{~h}$. The adherent population (enriched monocytes) was washed twice with RPMI 1640 to remove any remaining nonadherent cells. The adherent cells were then incubated in $1 \mathrm{ml}$ of complete medium for $48 \mathrm{~h}$. The adherent population was subsequently stained for the monocyte/macrophage-specific enzyme $\alpha$-naphtyl acetate esterase and was found to be $>95 \%$ monocytes. Monocytes composed $19.5 \pm 4.1 \%$ of the entire original mononuclear population isolated by Ficoll density gradient centrifugation. In all experiments, at the end of the 48-h incubation, conditioned media were collected and assayed for endotoxin by the chromogenic Limulus amebocyte lysate assay (Whittaker M.A. Bioproducts, Walkersville, MD). Endotoxin was not detected at the level of sensitivity of the assay $(\geq 10 \mathrm{pg} / \mathrm{ml})$. The media were then passed through $0.22-\mu \mathrm{m}$ filters and stored at $-20^{\circ} \mathrm{C}$ until assayed for IL-1.

IL-1 assay. The PBMC-conditioned media were assayed for IL-1 activity (IL- $1 \alpha$ and IL- $1 \beta$ ) by assessing the increment in mitogen-induced proliferation of the helper T cell D10.G4.1 (D.10 cells) as previously described $(20,21,26)$. The IL-1 standard used in the assays was ultrapure IL-1 (Genzyme, Boston, MA), except for the IL-1 used in the neutralization assay, which was recombinant IL- $1 \alpha$ or IL- $1 \beta$ (Genzyme). The IL-1 activity, measured by quantitating the thymidine incorporation in the D. 10 cells, was converted to units per milliliter by performing a log-logit transformation of the serial dilution curves and determining the dilution of the test sample that yielded a value corresponding to $50 \%$ of the standard IL-1 maximum activity. The standard IL-1 activity was arbitrarily set at $100 \mathrm{U} / \mathrm{ml}$. The test sample units were then determined as follows: Activity (semple) $=2^{(a-b)} \times 100$ $\mathrm{U} / \mathrm{ml}_{\text {(standard IL-1) }}$, where $a$ is the dilution of the test sample yielding $50 \%$ of the standard IL-1 activity and $b$ is the dilution of the standard IL-1 yielding 50\% maximal activity.

The interassay and the intrassay variability of this assay was $29 \%$ and $10 \%$, respectively. Recovery of added recombinant IL- $1 \beta$ was $\geq 90$. The minimum amount of lipopolysaccharide (LPS) capable of stimulating IL-1 secretion was $10-100 \mathrm{pg} / \mathrm{ml}$.

Since PBMC may secrete agents in addition to IL-1 that are comitogenic in the T cell assay (27-29), we verified our findings as indicative of the presence of IL-1 by demonstrating inhibition of the PBMC-conditioned media effect in the presence of monoclonal anti-IL- $1 \alpha$ and anti-IL- $1 \beta$ antibodies (kindly provided by John Kenney, Syntex Corp., Palo Alto, CA). These neutralization experiments were performed by incubating serial dilutions of the PBMC culture medium for $2 \mathrm{~h}$ with anti-IL-1 $\alpha$ (1:20 dilution), anti-IL-1 $\beta$ ( $1: 200$ dilution), or control serum at $37^{\circ} \mathrm{C}$ before assay of the D. 10 cells.

Preparation of test materials. Intact type I collagen was extracted from rat tails according to the method of Piez et al. (30). Heat-denatured type I guinea pig skin collagen was prepared as previously described (31). Denatured type I collagen peptides were produced by di- gesting heat-denatured guinea pig skin collagen with purified rat uterus collagenase as previously described (31). Human $\alpha_{2} \mathrm{HS}$ glycoprotein $(49,000 \mathrm{~mol} \mathrm{wt})$ was isolated from human serum as previously described (25). Purified bovine osteocalcin (BGP), extracted from lyophilized bone with EDTA and purified by gel filtration as described by Price et al. (32), was kindly provided by Dr. P. Price (University of California, San Diego). Purified bovine TGF- $\beta$ was kindly provided by Dr. Saeid Seyedin (Collagen Corp., Palo Alto, CA). Purified bovine fibronectin was kindly provided by Dr. John A. McDonald (Washington University School of Medicine, St. Louis, MO). Adherence promoting Arg-Gly-Asp (RGD)-containing fragments of synthetic bone sialoprotein (18 aminoacids) and osteopontin (20 aminoacids) were kindly provided by Dr. Pamela Robey (National Institutes of Health, Bethesda, MD). Commercial $50-\mu \mathrm{m}$ hydroxyapatite crystals were washed extensively, sterilized, and suspended at $10 \mathrm{mg} / \mathrm{ml}$ in pyrogenfree phosphate-buffered saline (PBS).

For some experiments, hydroxyapatite and heat-denatured collagen were hydrolyzed with $0.01 \mathrm{~N} \mathrm{NaOH}$ in $90 \%$ ethanol at $37^{\circ} \mathrm{C}$ for 60 min, with frequent mixing (33). The reaction was arrested by neutralizing with acetic acid and reducing the sample temperature to $4^{\circ} \mathrm{C}$. Control samples were incubated in $90 \%$ ethanol without $\mathrm{NaOH}$. Collagen was resuspended and neutralized by dialysis against acetic acid, phosphate buffer, and normal saline.

All test materials contained $<10 \mathrm{pg} / \mathrm{ml}$ endotoxin in the Limulus amebocyte lysate assay (data not shown).

Bone particle preparation. Human and rat devitalized bone particles were prepared as previously described by Teitelbaum et al. (34). Briefly, human ribs or rat long bones were dissected free of periosteum and soft tissue, split to expose the marrow cavity, washed extensively with sterile $0.9 \% \mathrm{NaCl}$, and air-dried for $1 \mathrm{wk}$ at $45^{\circ} \mathrm{C}$. The bones were then ground in a mill (Spex Industries, Inc., Metuchen, NJ) and particles $<50 \mu \mathrm{m}$ in diameter were collected by passing the coarse powder through a screen (Cistron Corp., Lebanon, PA). These particles were then sterilized by ultraviolet irradiation. Nondevitalized human and rat bone particles were prepared in a similar manner by using sterile equipment and by omitting the air drying and the ultraviolet irradiation steps. Osteoblast-covered human and rat bone particles were prepared by maintaining the live bone particles in culture for 7-10 d. Under these conditions, cells gradually grew on the surface of the particles covering the entire matrix surface. These cells were characterized as osteoblasts because they were intensively positive for alkaline phosphatase and Van Kossa staining and, when isolated by collagenase digestion, secreted cAMP in response to PTH (data not shown). Chicken osteoclast-covered bone particles were prepared by incubating devitalized rat bone particles with chicken osteoclasts, isolated according to the methods of Zambonin-Zallone et al. (35) and Blair et al. (36) for 18 $h$ at $37^{\circ} \mathrm{C}$. The bone particles and attached osteoclasts were then separated from unbound cells by unit gravity sedimentation in PBS for 10 $\min$ at $27^{\circ} \mathrm{C}$. In some experiments, bone particles were preincubated with 1-hydroxy-1,1 ethane diphosphate (EHDP), or etidronate (Norwich Eaton Pharmaceuticals, Inc., Norwich, NY), $80 \mu \mathrm{mol}$ for $24 \mathrm{~h}$ at $37^{\circ} \mathrm{C}$. The EHDP-treated bone particles were then pelleted by centrifugation and washed twice with fresh medium. In all the experiments carried out using PBMC cultures or lymphocyte-enriched preparations, the tissue culture plates were coated with a thin layer of the bone particle of choice. The cells were then added and cultured for $48 \mathrm{~h}$. Similar results were obtained whether test cells were added before or after bone particles (data not shown). In the experiments with monocyte-enriched preparations, the same amount of bone particles was added to the adherent monocytes after the removal of the non-adherent mononuclear cells. The optimal concentration of bone particles $(1 \mathrm{mg} /$ $\mathrm{ml}$ ) was determined before the study. Increasing the bone particle concentration as much as 10-fold did not alter the results. However, decreasing the amount of bone particles so that about $\geq 30 \%$ of the culture well surfaces were not covered decreased the mononuclear cell response.

Antibodies. The P1H5 monoclonal antibody directed against the $\alpha_{2} \beta_{1}$-integrin cell surface collagen receptor was generously provided by 


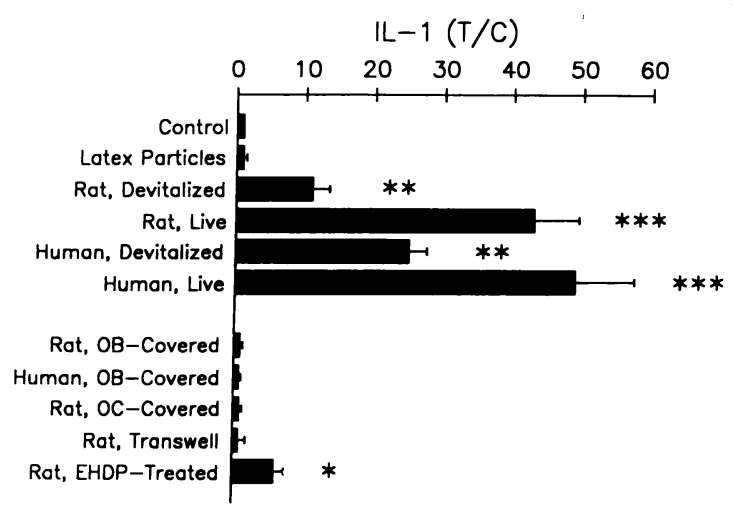

Figure 1. IL-1 activity in the culture medium of PBMC co-cultured with either rat or human bone particles. IL-1 activity in the culture media of unstimulated PBMC (controls) was $2.1 \pm 0.9 \mathrm{U} / \mathrm{ml}$. To allow comparisons of data from different experiments, results are shown as treated/control (T/C) ratio. Abbreviations: OB, osteoblasts; OC, osteoclasts; EHDP, etidronate. "Transwell" refers to experiments carried out in a culture system where PBMC were separated from the bone particles by a membrane permeable to the culture medium only. ${ }^{*} P<0.05 ;{ }^{* *} P<0.01 ;{ }^{* * *} P<0.001$ compared to controls.

Dr. William G. Carter, Fred Hutchinson Cancer Research Center, Seattle, WA. Monoclonal antibody 10E5 directed against the platelet membrane glycoprotein IIb-IIIa complex was kindly provided by Dr. Barry S. Coller, State University of New York, Stony Brook, NY. The characterization and specificity of both antibodies have been previously documented $(37,38)$. Both antibodies were used in IL-1 release assays at a concentration of $10 \mu \mathrm{g} / \mathrm{ml}$.

Statistical methods. Group mean values were compared by twotailed Student's test or analysis of variance, as appropriate. Subsequent mean comparison tests were performed by Tukey's honestly significant difference test.

\section{Results}

Bone particles stimulate the secretion of IL-1 from normal human PBMC. In a set of 25 experiments (Fig. 1), IL-1 activity in the culture media of unstimulated PBMC incubated in plastic culture wells for $48 \mathrm{~h}$ was $2.1 \pm 0.9 \mathrm{U} / \mathrm{ml}$ (mean $\pm \mathrm{SEM}$ ) (median 0.39 , range 0.1-16.4).

A similar amount of IL-1 was released into the medium by PBMC cultured over a layer of $\sim 50-\mu \mathrm{m}$ latex particles (Fig. 1). In this condition PBMC adhered strongly to but did not phagocytize the latex particles. PBMC co-cultured with similar amounts of devitalized or live rat or human bone particles adhered to the bone particles and released significantly higher amounts of IL- 1 in the culture media. Devitalized human particles were more potent in inducing IL-1 activity than devitalized rat particles (25.0- vs. 11.1-fold increase, respectively). However, the highest IL-1 activities were found in the media of PBMC co-cultured with live rat (43-fold increase) and human (49-fold increase) bone particles, suggesting that soluble factors released by osteocytes within the bone particles contribute to the enhanced IL-1 activity.

In order to determine whether a physical contact between PBMC and bone surface is required to activate IL-1 release, PBMC were co-cultured with osteoblast-covered human or rat particles or osteoclast-covered rat bone particles. Under these conditions, PBMC were in close contact with the bone cells covering the particles, but were separated from the matrix surface itself. In each of these experiments, IL-1 activity was similar to that in control PBMC cultures, suggesting that IL-1 secretion requires the physical contact of PBMC to specific constituents of the bone surface. Conditioned media from osteoblast- or osteoclast-covered bone cultures did not demonstrate a decreased PBMC response to uncovered bone particles nor a diminished ability of recombinant IL- $1 \beta$ to stimulate D. 10 cells proliferation (data not shown). These findings suggest that cells covering the bone particles did not secrete factor(s) that inhibit PBMC IL-1 release.

To confirm that physical contact of PBMC and bone is required for inducing the PBMC response to bone, experiments were carried out with a transwell culture system in which PBMC and devitalized rat bone particles were incubated in two chambers divided by a membrane (pore size $0.4 \mathrm{~mm}$ ) permeable to the culture media, but which prohibited cell-bone contact. Under these conditions, the IL-1 activity in the transwell cultures was similar to the activity in control PBMC cultures.

To assess whether interferences with the attachment of PBMC to bone surface affect IL-1 release, devitalized rat bone particles were pretreated for $48 \mathrm{~h}$ with EHDP, a substance that decreases the binding of PBMC and osteoclasts to the bone surface $(39,40)$. As shown in Fig. 1, pretreatment with EHDP $(80 \mu \mathrm{mol})$ significantly decreased the ability of rat bone particles to stimulate IL-1 release. To investigate whether a toxic effect of EHDP on PBMC may have accounted for those findings, phytohemagglutinin (PHA)-stimulated PBMC were incubated with concentrations of EHDP (Table I) up to fivefold higher than those used to pretreat the bone particles. This treatment resulted in no significant change in the amount of IL-1 released into the culture media. Similarly, EHDP did not decrease the ability of guinea pig type I collagen (see below and Table I) to increase IL-1 activity from unstimulated PBMC.

To determine whether bone particles induce IL-1 release from monocytes, lymphocytes, or both, devitalized rat bone particles were co-cultured with adherent monocytes or lymphocytes depleted of monocytes. In each of five experiments (Table II), monocytes but not lymphocytes adhered to the bone particles and released increased amounts of IL-1.

Effect of bone matrix constituents on PBMC IL-1 activity. To investigate the nature of the bone constituent(s) accounting for the release of IL-1, PBMC were incubated with various

Table I. Effect of EHDP on IL-1 Release from PBMC Stimulated with PHA $(1 \mu \mathrm{g} / \mathrm{ml})$ or with Guinea Pig Heat-denatured Type I Skin Collagen

\begin{tabular}{rccl}
\hline & \multicolumn{3}{c}{ Stimulants } \\
\cline { 2 - 4 } EHDP & None & PHA & Type I collagen \\
\hline$\mu M$ & & $U / m l$ & \\
- & $3.9 \pm 0.8$ & $4,364 \pm 426$ & $3,628 \pm 946$ \\
25 & $3.1 \pm 0.9$ & $3,911 \pm 398$ & $3,711 \pm 1,001$ \\
50 & $4.2 \pm 0.7$ & $4,469 \pm 422$ & $3,601 \pm 880$ \\
100 & $3.6 \pm 0.9$ & $4,304 \pm 480$ & $3,395 \pm 972$ \\
200 & $3.2 \pm 0.6$ & $4,732 \pm 401$ & $3,983 \pm 1,057$ \\
400 & $4.1 \pm 0.8$ & $3,913 \pm 422$ & $3,661 \pm 1,112$
\end{tabular}

PBMC were incubated with EHDP and either PHA or guinea pig type I collagen for $48 \mathrm{~h}$. The culture medium was then assayed for IL-1. Data are reported as mean \pm SEM. 
Table II. Effect of Devitalized Rat Bone Particles on IL-1 Activity from Peripheral Blood Monocytes, Lymphocytes, and Total Mononuclear Cells (PBMC)

\begin{tabular}{lccc}
\hline & \multicolumn{3}{c}{ IL-1 activity } \\
\cline { 2 - 4 } \multicolumn{1}{c}{ Group } & Monocytes & Lymphocytes & \multirow{2}{*}{ PBMC } \\
\hline & & $U / m l$ \\
Unstimulated cells & $0.1 \pm 0.1$ & $0.1 \pm 0.1$ & $2.1 \pm 0.3$ \\
Cells + rat bone particles & $56.7 \pm 9.5^{*}$ & $1.9 \pm 1.4$ & $69.4 \pm 8.3^{*}$
\end{tabular}

Data are reported as mean \pm SEM.

${ }^{*} P<0.01$, compared to unstimulated cells.

purified bone substances. In a first set of experiments, PBMC were cultured in a well coated with a gel of intact rat tail type I collagen or a layer of hydroxyapatite crystals. Assays of the resulting conditioned media revealed an increase in IL-1 activity with both substances (Table III). However, the response elicited by collagen was higher than the one induced by hydroxyapatite. Preincubation of hydroxyapatite with EHDP (80 $\mu \mathrm{mol}$ ) reduced by $65 \%$ the stimulatory effect on IL-1 activity, further indicating that EHDP may prevent IL-1 release by a specific physicochemical interaction with PBMC and hydroxyapatite.

In a second set of experiments, dose-response curves were generated by incubating PBMC with one of the following: a soluble preparation of heat-denatured guinea pig type I skin collagen or type I collagen fragments produced by the action of rat uterus collagenase on heat-denatured collagen (Fig. 2, left), hydroxyapatite crystals, TGF- $\beta, \alpha_{2}$ HS glycoprotein, osteocalcin, fibronectin, bone sialoprotein fragments, or osteopontin fragments. Guinea pig type I denatured collagen and collagen fragments both induced a significant $(P<0.001)$ increase in the amount of IL-1 released into the culture media. As shown in Fig. 2 (right), the magnitude of the response was dose dependent within the range tested $(0.5-150 \mu \mathrm{g} / \mathrm{ml})$. However, the collagen fragments produced by either a 2- or a 4-h digestion with mammalian collagenase were even more potent $(P$ $<0.05$ ) than intact collagen in inducing IL-1 release. Conversely, the amount of IL-1 released into the culture media after incubation with either 24- or 48-h digested fragments was

Table III. Effect of Rat Tail Type I Collagen, Hydroxyapatite, and EHDP-treated Hydroxyapatite on PBMC IL-1 Activity

\begin{tabular}{lccc}
\hline \multicolumn{1}{c}{ Group } & IL-1 & $\begin{array}{c}\text { Treated/control } \\
\text { IL-1 activity }\end{array}$ \\
\hline & & $U / m l$ & \\
Controls & $1.1 \pm 0.2$ & - \\
Collagen & $4,964.2 \pm 359.6^{*}$ & 4,513 \\
Hydroxyapatite & $1,175.3 \pm 281.2^{\ddagger}$ & 1,068 \\
EHDP-hydroxyapatite & $411.2 \pm 98.6^{\ddagger}$ & 374
\end{tabular}

PBMC were incubated in culture wells coated with a collagen gel of rat tail type I collagen or a layer of hydroxyapatite crystals for $48 \mathrm{~h}$.

The culture medium was then assayed for IL-1. Data are reported as mean \pm SEM.

${ }^{*} P<0.001 ;{ }^{\ddagger} P<0.01$, compared to controls. lower than that elicited with intact collagen (Fig. 2, right). When PBMC were incubated with hydroxyapatite (Fig. 3), a dose-dependent stimulatory effect was also observed. However, the maximal response elicited by hydroxyapatite was significantly lower $(P<0.05)$ than that induced by either heatdenatured type I collagen or its fragments.

To assess whether collagen and hydroxyapatite induce the secretion of IL- $1 \alpha$, IL- $1 \beta$, or both, PBMC culture media were incubated with monoclonal antibodies against human IL-1 $\alpha$ and IL1- $\beta$. The results (Table IV) showed an almost complete inhibition of biological activity with the anti-IL-1 $\beta$ antibody and a partial reduction with the anti-IL-1 $\alpha$ antibody, indicating that IL- $1 \beta$ was indeed responsible for the majority of the D. 10 cell proliferation activity.

Incubation of PBMC with purified bovine TGF- $\beta$ induced a significant but much less substantial increase in IL-1 activity (Fig. 3). This response was dose dependent between 1 and 10 $\mathrm{ng} / \mathrm{ml}$, optimal at $10 \mathrm{pg} / \mathrm{ml}$, and was abolished by boiling the TGF- $\beta$ preparation for $10 \mathrm{~min}$. Conversely, IL- 1 activity was not stimulated by osteocalcin $(0.1 \mathrm{ng} / \mathrm{ml}$ to $1 \mu \mathrm{g} / \mathrm{ml}), \alpha_{2} \mathrm{HS}$ glycoprotein $\left(10^{-12}\right.$ to $\left.10^{-5} \mathrm{M}\right)$, fibronectin $(0.1-100 \mu \mathrm{g} / \mathrm{ml})$, bone sialoprotein fragments $(0.1-100 \mu \mathrm{g} / \mathrm{ml})$, or osteopontin fragments $(0.1-100 \mu \mathrm{g} / \mathrm{ml})$. The effect of fibronectin, osteopontin, and bone sialoprotein on IL-1 release was also investigated by culturing PBMC in wells coated with each of these agents. The dose responses obtained with these experiments were similar to those obtained by dissolving the test substances in PBMC cultures (data not shown).

$A$ monoclonal antibody which recognizes the $\alpha_{2} \beta_{1}$ collagen receptor blocks the collagen-induced increase in $I L-1$ activity. To determine whether a specific receptor mediates the IL-1 response to collagen, antibody neutralization experiments were performed. As shown in Fig. 4, the P1H5 monoclonal antibody directed against the $\alpha_{2} \beta_{1}$-integrin, a cell surface collagen receptor, significantly decreased the IL- 1 release in response to heatdenatured collagen but not to both hydroxyapatite and LPS. The spontaneous release of IL-1 from unstimulated PBMC was also not affected by the P1H5 antibody. These findings suggest that the IL-1 release induced by collagen is mediated, at least in part, by the $\alpha_{2} \beta_{1}$-integrin. The control antibody, 10E5, had no effect on the IL-1 released in response to collagen.

To investigate the contribution of the $\alpha_{2} \beta_{1}$ receptor to the release of IL-1 induced by the adherence of PBMC to bone particles, PBMC were co-cultured with devitalized bone particles and either the P1H5 or the 10E5 antibody. The antibody P1H5 decreased, although not significantly, the IL-1 release induced by rat bone particles, suggesting that interaction with the $\alpha_{2} \beta_{1}$-integrin receptor is one, but not the exclusive, mechanism by which bone particles stimulate PBMC IL-1 release.

Polymixin $B$ and alkaline hydrolysis do not abolish the $P B M C$ response to collagen and hydroxyapatite. LPS is one of the most potent stimulants of IL-1 release from PBMC (41). To rule out the possibility that contamination with levels of LPS below the limit of detection of the Limulus amebocyte lysate assay $(<10 \mathrm{pg} / \mathrm{ml})$ might have accounted for the IL-1 stimulatory activity observed with our collagen and hydroxyapatite preparations, we cultured PBMC with these bone constituents and polymixin $\mathrm{B}$ (PB). PB is a polypeptide antibiotic which, at low concentrations, blocks many effects of LPS on immune cells including IL-1 release (42). Although at high concentrations PB may directly stimulate IL-1 secretion (43), concentrations $\leq 0.5 \mu \mathrm{g} / \mathrm{ml}$ effectively block levels of LPS $\leq 1 \mathrm{ng} / \mathrm{ml}$ 

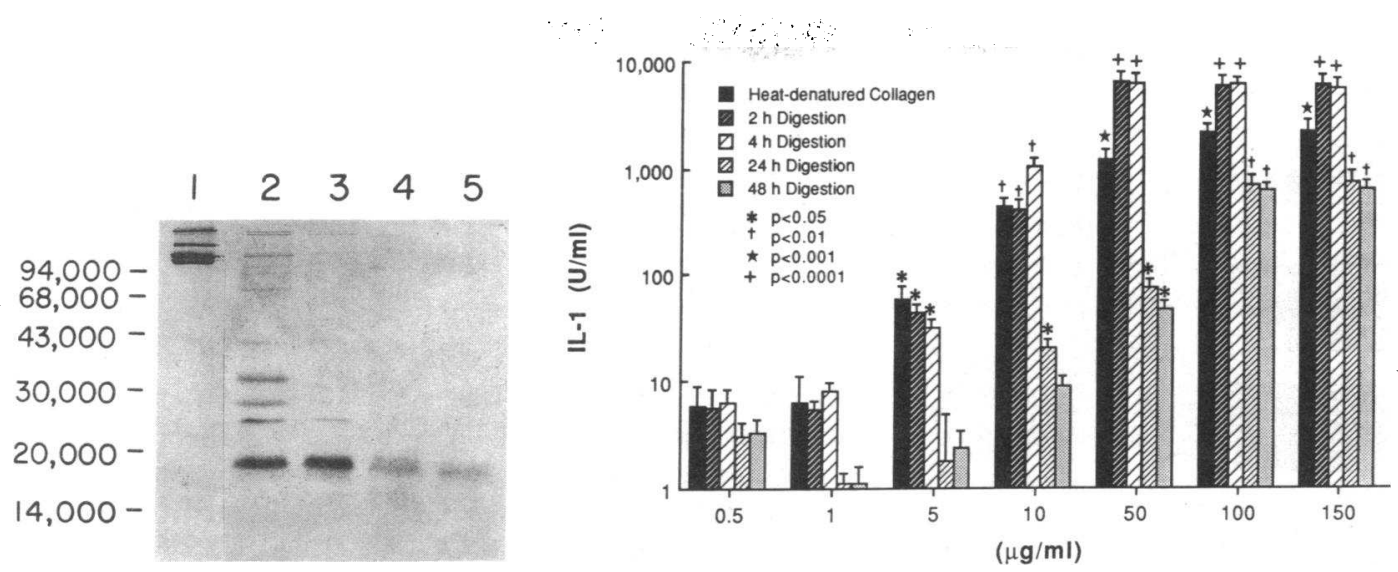

Figure 2. (Left) SDS-

PAGE of heatdenatured guinea pig type I skin collagen before and after rat uterus collagenase digestion. Purified guinea pig skin type I collagen $(1.5 \mathrm{mg} / \mathrm{ml})$ in $0.05 \mathrm{M}$ Tris, $\mathrm{pH}$ 7.5, $0.01 \mathrm{M} \mathrm{CaCl}_{2}$ was denatured by heating to $90^{\circ} \mathrm{C}$ for $15 \mathrm{~min}$ and supplemented with penicillin $(200 \mathrm{U} / \mathrm{ml})$ and streptomycin (200

$\mu \mathrm{g} / \mathrm{ml}$ ). Purified rat uterus collagenase was added to a final concentration of $20 \mu \mathrm{g} / \mathrm{ml}$, and the mixture was filtered through a $0.2-\mu \mathrm{m}$ membrane. Incubation was performed at $37^{\circ} \mathrm{C}$. At the times indicated, $100-\mu \mathrm{l}$ samples were removed under sterile conditions and chilled to $0^{\circ} \mathrm{C}$ to stop the reaction. $15 \mu$ l of each sample was mixed with sample buffer and subjected to PAGE, using a $15 \%$ gel. The gel was stained with Coomassie Brilliant Blue. Slot 1 , heat-denatured collagen; slots $2-5$, heat-denatured collagen incubated with enzyme for $2,4,24$, and $48 \mathrm{~h}$, respectively. Molecular weight markers shown at left. (Right) Effect of heat-denatured guinea pig type I collagen and collagenase-digested collagen fragments on PBMC IL-1 activity. ${ }^{*} P<0.05 ;{ }^{\dagger} P<0.01 ;{ }^{\star} P<0.001,{ }^{+} P<0.0001$ compared to controls. The PBMC response to either 2- or 4-h digested collagen fragments was significantly higher $(P>0.05)$ than the response to undigested heat-denatured collagen at $50-150 \mu \mathrm{g} / \mathrm{ml}$. The PBMC response to 24- and 48-h digested fragments was significantly lower $(P<0.05)$ than the response to either undigested, 2-, or 4-h digested heat-denatured collagen for concentrations $\geq 10 \mu \mathrm{g} / \mathrm{ml}$.

(42). As shown in Table V, PB inhibited the LPS- but not the collagen- or the hydroxyapatite-induced PBMC response, indicating lack of a significant LPS contamination. Another potential contaminant of our test materials is lipid A-associated protein (LAP), a monocyte stimulatory peptide noncovalently bound to LPS $(44,45)$. LAP is not blocked by $P B(44,45)$ but is inactivated by mild alkaline hydrolysis (32). The presence of a significant LAP contamination was excluded by the inability of $\mathrm{NaOH}$ hydrolysis to decrease the secretion of IL-1 induced by both collagen and hydroxypatite (Table V). The presence of LPS or other soluble IL-1 stimulatory factors such as LAP in the preparations described above was further ruled out by the lack of a stimulatory effect of boiled TGF- $\beta$ preparations and the finding that supernatant fluids from both hydroxyapatite and collagen suspensions did not stimulate PBMC to release

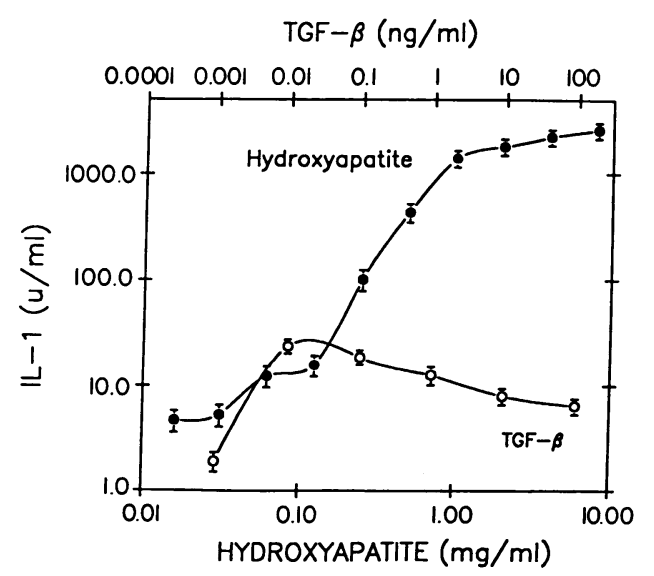

Figure 3. Effect of hydroxyapatite (๑) and TGF $\beta$ (०) on PBMC IL-1 activity. The PBMC response to hydroxyapatite was significant at $P$ $<0.05$ for concentrations $\geq 0.25 \mathrm{mg} / \mathrm{ml}$ and at $P<0.0001$ for concentrations $\geq 1 \mathrm{mg} / \mathrm{ml}$. The PBMC response to TGF- $\beta$ was significant $(P<0.05)$ at $0.01 \mathrm{ng} / \mathrm{ml}$ and was abolished by boiling for $10 \mathrm{~min}$ (data not shown).
IL-1 activity (data not shown). Similarly, the presence of bound LPS was excluded by the inability of hydroxyapatite and collagen preparations to decrease the PBMC response to added LPS (data not shown).

\section{Discussion}

In this study, we have shown that attachment of PBMC or adherent monocytes to the bone matrix surface is associated with a marked stimulation of IL- 1 release. The data also indi-

Table IV. Neutralization of PBMC IL-1 Activity with Monoclonal Anti-Human IL-I $\alpha$ and IL-I Antibodies

\begin{tabular}{lccc}
\hline & \multicolumn{3}{c}{ Antibody } \\
\cline { 2 - 4 } \multicolumn{1}{c}{ Stimulant } & None & Anti-IL-1 $\alpha$ & Anti-IL-1 $\beta$ \\
& & $U / m l$ \\
None & & & \\
$\quad$ IL-1 $\alpha$ & $280 \pm 20$ & 0 & $200 \pm 31$ \\
IL-1 $\beta$ & $394 \pm 52$ & $288 \pm 41$ & $11 \pm 1$ \\
Collagen $(100 \mu \mathrm{g} / \mathrm{ml})$ & & & \\
1:1 & $3,182 \pm 201$ & $2,110 \pm 253$ & $423 \pm 49$ \\
1:4 & $1,080 \pm 121$ & $526 \pm 52$ & $56 \pm 4$ \\
1:16 & $115 \pm 16$ & $88 \pm 9$ & $15 \pm 2$ \\
Hydroxyapatite $(8 \mathrm{mg} / \mathrm{ml})$ & & & \\
$1: 1$ & $2,121 \pm 349$ & $1,475 \pm 180$ & $67 \pm 15$ \\
$1: 4$ & $507 \pm 70$ & $292 \pm 31$ & $40 \pm 3$ \\
$1: 16$ & $67 \pm 11$ & $59 \pm 4$ & $9 \pm 2$ \\
& & & \\
\hline
\end{tabular}

Conditioned media derived from PBMC cultured with collagen (100 $\mu \mathrm{g} / \mathrm{ml})$ or hydroxyapatite $(8 \mathrm{mg} / \mathrm{ml})$ were serially diluted and assayed for their ability to induce D. 10 cell proliferation in the absence or the presence of neutralizing antibodies to IL-1 $\alpha$ or IL-1 $\beta$. Conditioned medium $(100 \mu \mathrm{l})$ was incubated with a 1:20 dilution of anti-IL-1 $\alpha$ antibody or a 1:200 dilution of anti-IL-1 $\beta$ for $2 \mathrm{~h}$ and then assayed for D. 10 cell proliferation (final volume $200 \mu \mathrm{l}$ ). 


\section{IL-1 (\% change)}

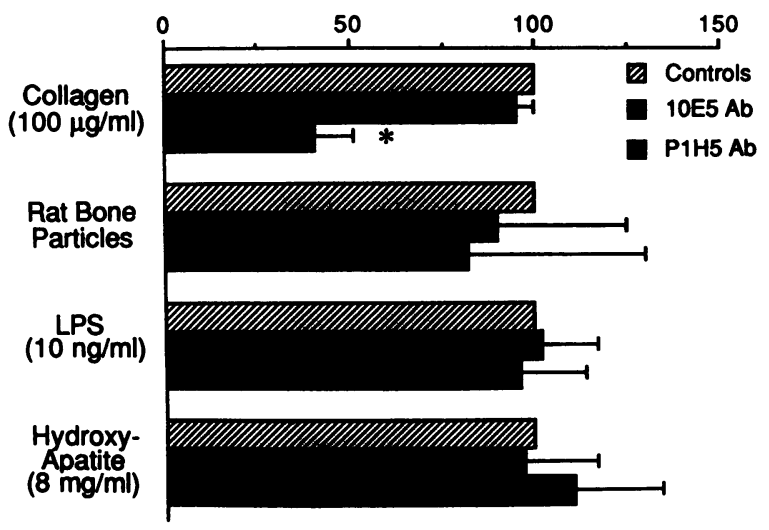

Figure 4. Effect of the monoclonal antibody P1H5 directed against the $\alpha_{2} \beta_{1}$-integrin cell surface collagen receptor on IL-1 activity induced by collagen $(100 \mu \mathrm{g} / \mathrm{ml})$, hydroxyapatite $(8 \mathrm{mg} / \mathrm{ml})$, LPS $(10$ $\mathrm{ng} / \mathrm{ml})$, and devitalized rat bone particles $(1 \mathrm{mg} / \mathrm{ml})$. PBMC were preincubated in the presence of the indicated antibody $(10 \mu \mathrm{g}$ antibody $/ \mathrm{ml}$ final concentration) for $2 \mathrm{~h}$. Test substances were then added and the incubation continued for an additional $46 \mathrm{~h}$. Since there was considerable variation in IL-1 response between the substances tested in these experiments, the control IL-1 activity was set at $100 \%$ and compared to that measured in the medium of PBMC cultured with the individual test substances and the P1H5 antibody. A control antibody $10 \mathrm{E} 5$, directed against the platelet membrane IIb-IIIa complex had no effect. The spontaneous release of IL-1 from unstimulated PBMC (3.2 $\pm 1.1 \mathrm{U} / \mathrm{ml})$ was not affected by either P1H5 or the $10 \mathrm{E} 5$ antibody (data not shown). ${ }^{*} P<0.05$ compared to controls.

cate that the major constituents of bone, collagen, hydroxyapatite, and to a lesser extent, TGF- $\beta$, can all stimulate IL- 1 activity.

The release of IL-1 from PBMC was not an expression of a non-specific immune response to heterologous material, since both rat and human bone particles stimulated IL- 1 release from PBMC, and since IL-1 failed to increase when PBMC

Table V. Effect of PB and Mild Alkaline Hydrolysis on LPS, Collagen, and Hydroxyapatite-induced IL-1 Activity

\begin{tabular}{llcc}
\hline \multicolumn{1}{c}{ Stimulant } & PB & IL-1 & $\begin{array}{c}\text { Percent change with } \\
\text { alkaline hydrolysis }\end{array}$ \\
\hline & $\mu g / m l$ & $U / m l$ & \\
None & 0 & $8.4 \pm 2.3$ & - \\
LPS $(1 \mathrm{ng} / \mathrm{ml})$ & 0.5 & $6.9 \pm 3.1$ & - \\
& 0 & $669 \pm 80$ & $-67 \pm 5^{*}$ \\
Collagen $(100 \mu \mathrm{g} / \mathrm{ml})$ & 0.5 & $95 \pm 11$ & $-68 \pm 4^{*}$ \\
& 0 & $2,548 \pm 301$ & $-10 \pm 4$ \\
Hydroxyapatite $(8 \mathrm{mg} / \mathrm{ml})$ & 0 & $1,750 \pm 221$ & $15 \pm 7$ \\
& 0.5 & $2,700 \pm 345$ & $18 \pm 6$ \\
& $0.528 \pm 202$ & $-16 \pm 5$ \\
\hline
\end{tabular}

Data are reported as mean \pm SEM. Collagen and hydroxyapatite were hydrolyzed with $0.01 \mathrm{~N} \mathrm{NaOH}$ in $80 \%$ ethanol at $37^{\circ} \mathrm{C}$ for $60 \mathrm{~min}$. Control samples were incubated in $90 \%$ ethanol without $\mathrm{NaOH}$ for 60 min and retained $\geq 80 \%$ of the original activity.

${ }^{*} P<0.01$ compared to controls. were in physical contact with rat osteoblasts or chicken osteoclasts but could not adhere to the bone matrix surface. The results of the experiments with test substances treated with PB, alkaline hydrolysis, or boiling, and the inability of the suspension fluids to stimulate PBMC IL-1 release suggest that contamination with low levels of LPS or LAP is an unlikely explanation for our findings.

Stimulation of IL-1 activity appeared to be the result of a specific PBMC-bone surface interaction. Increased IL-1 activity was not observed, in fact, when PBMC were co-cultured with latex particles, to which cells strongly adhere. Although the intimate nature of this interaction remains unknown, attachment of the cells to the bone surface appears to be an essential step. Nonadherent monocyte-depleted lymphocytes were not stimulated to release IL-1 and IL-1 secretion was not increased when bone surfaces and mononuclear cells were not in physical contact. Similarly, co-culture of PBMC with bone particles which had been pretreated with EHDP, an agent which reduces the bone binding capacity of both PBMC (39) and osteoclasts (40), decreased but did not abolish the PBMC response to bone. As previously observed in similar studies (46), the EHDP inhibition of IL-1 release was not the result of a toxic effect on PBMC, as indicated by the inability of EHDP to inhibit the secretion of IL-1 from cells stimulated with PHA or incubated with collagen.

Previous studies have shown that the attachment of monocytes to bone is analogous to that of osteoclasts and depends on the constituents of the bone matrix (47). Our findings support these concepts and indicate that not only adherence, but also the secretory activity of PBMC is regulated by specific matrix constituents. Two of these which we found to have high stimulatory activity were collagen fragments, the most abundant bone peptide, and hydroxyapatite, the mineral constituent of bone. Whether specific receptors mediate the interaction of PBMC with hydroxyapatite has yet to be determined. However, the ability of a specific monoclonal antibody, P1H5, to decrease the PBMC response to collagen suggests that the interaction between collagen and these cells is mediated, at least in part, by a specific collagen receptor, the $\alpha_{2} \beta_{1}$-integrin (48-50). This class of collagen receptor is indeed expressed on monocytes (49) and osteoclasts (51) but not on circulating lymphocytes (49). Moreover, the fact that products of short-term, but not long-term, collagenase digestion were more potent stimulators of IL- 1 activity than undigested material suggests that specific collagen domains were first exposed and then partially digested as the length of the collagenase digestion increased.

Two other bone constituents that possess chemotactic properties, $\alpha_{2} \mathrm{HS}$ glycoprotein and osteocalcin (23), failed to stimulate IL-1 activity. Similarly, IL-1 activity was not stimulated by fibronectin, a ubiquitous adherence protein (52), bone sialoprotein, or osteopontin fragments. Adherence proteins containing the Arg-Gly-Asp (RGD) sequence $(52,53)$, a trait recognized by some but not all integrin receptors $(48,49)$ and osteocalcin have been hypothesized to participate in cell attachment to mineralized matrix because they bind tightly to collagen (52) and hydroxyapatite (54) and because vitamin-K depletion prevents cell adherence to bone (55). Our data do not negate this possibility; rather they suggest important functional differences between the bone fragments produced with bone resorption. Substances such as adherence proteins and osteocalcin may, in fact, play a role in regulating the homing and the attachment of mononuclear cells to bone, whereas others, such as collagen 
fragments, may be particularly important for regulating the secretion of bone resorbing agents such as IL-1.

Although the regulation of bone remodeling is still conjectural at best, several lines of evidence suggest a role for IL-1 in either initiating or modulating this remodeling phenomenon. Recent studies in rodents have shown that IL-1 stimulates bone turnover both locally and systemically, causing bone loss and hypercalcemia $(10,11)$. Increased secretion of IL-1 from mononuclear cells has been reported in several conditions characterized by a high incidence of osteoporosis such as rheumatoid arthritis $(56,57)$ and endometriosis $(58,59)$. In previous studies, we have shown that high IL-1 activity in vitro is characteristic of patients with high-turnover osteoporosis (20) and of early postmenopausal women, in whom bone remodeling is typically vigorous (21). Moreover, elaboration of IL-1 from PBMC has been found to be regulated $(21,60,61)$ by estrogen and progesterone-substances well known for their bone-sparing effect. However, the mechanism(s) accounting for the release of IL-1 in states of high bone turnover remains to be elucidated. The results of this study suggest that collagen, hydroxyapatite, and possibly TGF- $\beta$ enhance the capacity of PBMC to release IL-1. Since these factors are mobilized during bone resorption $(23,62)$, and/or constitutively secreted by osteoblasts (63), IL-1 could be secreted during physiologic bone remodeling in specific sites upon activation of new remodeling units. Because of the autocrine effect of IL-1 (64) and its powerful activity as a bone resorber (7-11), it is possible that IL-1 could initiate a cascade of events that leads to a further production of IL-1 and to an amplification of bone resorption. In this regard, it is noteworthy that the largest increase in IL-1 activity was induced by collagen fragments, substances more likely than intact collagen to be released locally during bone remodeling. Should this be the case, bone turnover could be regulated both by the amounts of matrix fragments released locally and by the degree of PBMC responsiveness to these fragments. The latter type of regulation is suggested by the ability of ovarian steroids and $1,25(\mathrm{OH})_{2} \mathrm{D}_{3}$ to regulate PBMC IL-1 activity $(21,60,61)$ and the expression of collagen receptors on monocytic cells (65), respectively. In this model, the increase in bone turnover and IL-1 observed after the menopause could be visualized as the result of an enhanced responsiveness of mononuclear cells to the release of bone matrix fragments. Our findings, however, could also suggest that bone resorption is controlled by an IL-1 independent mechanism; the enhanced IL-1 activity observed in states of high bone turnover could be regarded as a consequence, rather than a cause, of increased bone resorption. Although this possibility cannot be discounted, it is unlikely that the substantial release of IL-1 that follows the adherence of mononuclear cells to bone surfaces would have no influence on bone resorption.

The accumulated data support the hypothesis of a major role for IL-1 in bone remodeling and provide a mechanism to explain, at least in part, the finding of increased IL-1 activity in patients with high bone turnover.

\section{Acknowledgments}

We thank Ms. Bernice Kaplan and Mr. James Havranek for secretarial and editorial assistance.

Dr. Mallone supported by a "Merit Review" grant from the Veterans Administration. Dr. Santoro is an Established Investigator of the
American Heart Association. This study was supported in part by grants from the National Osteoporosis Foundation and the National Institutes of Health (AR-39706).

\section{References}

1. Oppenheim, J. J., E. J. Kovacs, K. Matsuchima, and S. K. Durum. 1986. There is more than one interleukin-1. Immunol. Today. 7:45-56.

2. Dinarello, C. A. 1988. Biology of interleukin 1. FASEB (Fed. Am. Soc. Exp Biol.) J. 2:108-115.

3. Hanazawa, S., S. Amono, K. Nakada, Y. Ohmori, T. Myoshi, K. Hirose, and S. Kitano. 1987. Biological characterization of interleukin-1-like cytokine produced by cultured bone cells from newborn mouse calvaria. Calcif. Tissue Int. 41:31-37.

4. Smith, K. A., L. B. Lachman, J. J. Oppenheim, and M. F. Favata. 1980. The functional relationship of the interleukins. J. Exp. Med. 151:1551-1556.

5. Gillis, S., and S. B. Mizel. 1981. T-cell lymphoma model for the analysis of interleukin 1-mediated T-cell activation. Proc. Natl. Acad. Sci. USA. 78:11331137.

6. Dinarello, C. A. 1984. Interleukin-1. Rev. Infect. Dis. 6:51-95.

7. Gowen, M., D. D. Wood, E. J. Ihrie, M. K. B. McGuire, and R. G. G. Russel. 1983. An interleukin-1-like factor stimulates bone resorption in vitro. Nature (Lond.). 306:378-380.

8. Gowen, M., and G. R. Mundy. 1986. Actions of interleukin-1, interleukin2 , and interferon q on bone resorption in vitro. J. Immunol. 136:2478-2482.

9. Lorenzo, J. A., S. L. Sousa, C. Alander, L. G. Raisz, and C. A. Dinarello. 1987. Comparison of the bone-resorbing activity in the supernatants from phytohemagglutinin-stimulated human peripheral blood mononuclear cells with that of cytokines through the use of an antiserum to interleukin 1. Endocrinology. 121:1164-1170.

10. Sabatini, M., B. Boyce, T. Aufdemorte, L. Bonewald, and G. R. Mundy. 1988. Infusions of recombinant human interleukin 1 alpha and beta cause hypercalcemia in normal mice. Proc. Natl. Acad. Sci. USA. 85:5235-5239.

11. Boyce, B. F., T. B. Aufdemorte, I. R. Garrett, A. J. P. Yates, and G. R. Mundy. 1989. Effects of interleukin-1 on bone turnover in normal mice. Endocrinology. 125:1142-1150.

12. Gowen, M., D. D. Wood, and R. G. G. Russell. 1985. Stimulation of the proliferation of human bone cells in vitro by human monocyte products with interleukin-1 activity. J. Clin. Invest. 75:1223-1229.

13. Canalis, E. 1986. Interleukin-1 has independent effects on deoxyribonucleic acid and collagen synthesis in cultures of rat calvariae. Endocrinology. 118:74-81, 14.

14. Stashenko, P., F. E. Dewhirst, M. L. Rooney, L. A. Desjardins, and J. D. Heeley. 1987. Interleukin- $1 \beta$ is a potent inhibitor of bone formation in vitro. $J$. Bone Miner. Res. 2:559-565.

15. Ideda, E., M. Kusaka, Y. Hakeda, K. Yokota, M. Kumegawa, and S. Yamamoto. 1988. Effect of interleukin 1 beta on osteoblastic clone MC3T3 cells. Calcif. Tissue Int. 43:162-166.

16. Canalis, E. 1981. Effect of platelet-derived growth factor on DNA and protein synthesis in cultured rat calvaria. Metab. Clin. Exp. 30:970-975.

17. Hurley, M. M., P. Fall, J. R. Harrison, D. N. Petersen, B. E. Kream, and L. G. Raisz. 1989. Effects of transforming growth factor $\alpha$ and interleukin-1 on DNA synthesis, collagen synthesis, procollagen mRNA levels, and prostaglandin $\mathrm{E}_{2}$ production in cultured fetal rat calvaria. J. Bone Miner. Res. 4:731-736.

18. Pfeilschifter, J., and G. R. Mundy. 1987. Modulation of type $\beta$ transforming growth factor activity in bone cultures by osteotropic hormones. Proc. Natl. Acad. Sci. USA. 84:2024-2028.

19. Thomson, B. M., J. Saklatvala, and T. J. Chambers. 1986. Osteoblasts mediate interleukin 1 stimulation of bone resorption by rat osteoclasts. $J$. Exp. Med. 164:104-112.

20. Pacifici, R., L. Rifas, S. Teitelbaum, E. Slatopolsky, R. McCracken, M. Bergfeld, W. Lee, L. V. Avioli, and W. A. Peck. 1987. Spontaneous release of interleukin 1 from human blood monocytes reflects bone formation in idiopathic osteoporosis. Proc. Natl. Acad. Sci. USA. 84:4616-4620.

21. Pacifici, R., L. Rifas, R. McCracken, I. Vered, C. McMurtry, L. V. Avioli, and W. A. Peck. 1989. Ovarian steroid treatment blocks a postmenopausal increase in blood monocyte interleukin 1 release. Proc. Natl. Acad. Sci. USA. 86:2398-2402.

22. Mundy, G. R., J. Vavrani, W. Orr, M. D. Gondex, and P. Ward. 1978. Resorbing bone is chemotactic for monocytes. Nature (Lond.). 275:132-135.

23. Malone, J. D., S. L. Teitelbaum, G. L. Griffin, R. M. Senior, and A. J. Kahn. 1982. Recruitment of osteoclast precursors by purified bone matrix constituents. J. Cell Biol. 92:227-230.

24. Wahl, S. M., D. A. Hunt, L. M. Wakefield, N. McCartney-Francis, L. M. Wahl, A. B. Roberts, and M. S. Sporn. 1987. Transforming growth factor type $\beta$ induces monocyte chemotaxis and growth factor production. Proc. Natl. Acad. Sci. USA. 84:5788-5792. 
25. Malone, J. D., and M. Richards. 1987. $\alpha_{2} \mathrm{HS}$ glycoprotein is chemotactic for mononuclear phagocytes. J. Cell. Physiol. 132:118-124.

26. Kurt-Jones, E. A., D. I. Beller, S. B. Mizel, and E. R. Unanue. 1985 Identification of a membrane associated interleukin-1 in macrophage. Proc. Natl. Acad. Sci. USA. 82:1204-1208.

27. Kay, J., S. Porcelli, J. Tite, B. Jones, and C. A. Janeway, Jr. 1983. Both a monoclonal antibody and antisera specific for determinants unique to individual cloned helper $T$ cell lines can substitute for antigen and antigen-presenting cells in the activation of T cells. J. Exp. Med. 158:836-856.

28. Garman, R. D., K. A. Jacobs, S. C. Clark, and D. H. Raulet. 1987. B-cel stimulating factor 2 ( $\beta_{2}$ interferon) functions as a second signal for interleukin 2 production by mature murine T cells. Proc. Natl. Acad. Sci. USA. 84:7629-7633.

29. Kupper, T., M. Horowitz, F. Lee, R. Robb, and P. M. Flood. 1987. Autocrine growth of $T$ cells independent of interleukin 2: identification of interleukin 4 (IL 4, BSF-1) as an autocrine growth factor for a cloned antigen-specific helper T cell. J. Immunol. 138:4280-4287.

30. Piez, K. A., E. A. Eigner, and M. S. Lewis. The chromatographic separation and amino acid composition of the subunits of several collagens. 1963 Biochemistry. 2:58-66.

31. Welgus, H. G., G. A. Grant, J. C. Sacchettini, W. T. Roswit, and J. J. Jeffrey. 1985. The gelatinolytic activity of rat uterus collagenase. J. Biol. Chem. 260:13601-13606.

32. Price, P. A., A. S. Otsuka, J. W. Poser, J. Kristaponis, and N. Raman 1976. Characterization of a q-carboxyglutamic acid-containing protein from bone. Proc. Natl. Acad. Sci. USA. 73:1447-1451.

33. Niwa, M., K. C. Milner, E. Ribi, and J. A. Rudbach. 1969. Alteration of physical, chemical, and biological properties of endotoxin by treatment with mild alkali. J. Bacteriol. 97:1069-1077.

34. Teitelbaum, S. L., C. C. Stewart, and A. J. Kahn. 1989. Rodent peritonea macrophages as bone resorbing cells. Calcif. Tissue Int. 27:255-261.

35. Zambonin-Zallone, A., A. Teti, and M. V. Primavera. 1982. Isolated osteoclasts in primary culture: first observations on structure and survival in culture media. Anat. Embryol. 165:405-415.

36. Blair, H. C., A. J. Kahn, E. C. Crouch, J. J. Jeffrey, and L. L. Teitelbaum 1986. Osteoclasts resorb the organic and inorganic components of bone. J. Cell Biol. 102:1164-1172.

37. Wayner, E. A., and W. G. Carter. 1987. Identification of multiple cell adhesion receptors for collagen and fibronectin in human fibrosarcoma cells possessing unique $\alpha$ and $\beta$ subunits. J. Cell Biol. 105:1873-1884.

38. Coller, B. S. 1985. A new murine monoclonal antibody reports on activation-dependent change in the conformation and/or microenvironment of the platelet GP IIb/IIIa complex. J. Clin. Invest. 76:101-110.

39. Fleisch, H. 1983. Bisphosphonates: mechanism of action and clinical applications. In Bone and Mineral Research Annual 1, W. A. Peck, editor. Excerpta Medica, Amsterdam. 319-357.

40. Carano, A., S. L. Teitelbaum, J. D. Konsek, P. H. Schlesinger, and H. C. Blair. 1990. Bisphosphonates directly inhibit the bone resorption activity of isolated avian osteoclasts in vitro. J. Clin. Invest. 85:456-461.

41. Wood, D. D. 1977. Role of adherent cell products in immune-response. In Regulatory Mechanisms in Lymphocyte Activation. D. O. Lucas, editor. Proc 11th Leukocyte Cult. Conf. 117-136.

42. Wood, D. D., and P. M. Cameron. 1978. The relationship between bacterial and endotoxin and human B-cell activating factor. J. Immunol. 121:53-60.

43. Damais, C., C. Jupin, M. Parant and L. Chedid. 1987. Induction of human interleukin-1 production by polymixin B. J. Immunol. Methods. 101:51-56.

44. Doe, W. F., S. T. Yang, D. C. Morrison, S. J. Betz and P. M. Henson.

1978. Macrophage stimulation by bacterial lipopolysaccharides. II. Evidence for differentiation signals delivered by lipid A and by a protein rich fraction of lipopolysaccharides. J. Exp. Med. 148:557-568.

45. Morrison, D. C., and B. J. Curry. 1979. The use of polymyxin B and $\mathrm{C} 3 \mathrm{H} / \mathrm{HeJ}$ mouse spleen cells as criteria for endotoxin contamination. J. Immunol. Methods. 27:83-92.

46. Evequoz, V., U. Trechsel, and H. Fleisch. 1985. Effect of bisphosphonates on production of interleukin 1-like activity by macrophages and its effect on rabbit chondrocytes. Bone (NY). 6:439-444.

47. Osdoby, P., M. Martini, and A. I. Caplan. 1982. The development of long bones of the limb: cell and matrix interactions of osteoclasts and monocytes Proc. Clin. Biol. Res. 110B:229.

48. Hynes, R. O. 1987. Integrins: A family of cell surface receptor. Cell 48:549-554.

49. Hemler, M. E. 1988. Adhesive protein receptors on haematopoietic cells. Immunology Today. 9:109-113.

50. Buck, C. A., and A. F. Horwitz. 1987. Cell surface receptors for extra cellular matrix molecules. Annu. Rev. Cell Biol. 3:189-205.

51. Athanasou, N. A., and D. Soligo. 1990. White cells differentiation antigens. In Leucocyte Typing IV, W. Knapp, editor. Oxford University Press, Oxford.

52. Hynes, R. O. 1986. Fibronectins. Sci. Am. 254:42-51.

53. Oldberg, A., A. Franzen, and D. Heinegard. 1986. Cloning and sequence analysis of rat bone sialoprotein (osteopontin) cDNA reveals an Arg-Glu-Asp cell binding sequence. Proc. Natl. Acad. Sci. USA. 83:8819-8823.

54. Franzen, A., and D. Heinegard. 1985. In Chemistry and Biology of Mineralized Tissues, W. T. Butler, editor. EBSCO, Birmingham, England. 132-141.

55. Lian, J. B., K. Dunn, and L. L. Key, Jr. 1986. In vitro degradation of bone particles by human monocytes is decreased with the depletion of the vitamin K-dependent bone protein from the matrix. Endocrinology. 118:1636-1642.

56. Tan, P., A. Shore, P. Leary, and E. C. Keystone. 1984. Interleukin abnormalities in recently active rheumatoid arthritis. J. Rheumatol. 11:593-596.

57. Sambrook, P. N., and J. Reeve. 1988. Bone disease in rheumatoid arthritis. Clin. Sci. 74:225-230.

58. Fakih, H., B. Baggett, G. Holtz, K.-Y. Tsang J. C. Lee, and H. O. Williamson. 1987. Interleukin 1: a possible role in the infertility associated with endometriosis. Fertil. Steril. 47:213-217.

59. Comite, F. M. Delman, K. Hutchinson-Williams, A. H. DeCherney, and P. Jensen. 1989. Reduced bone mass in reproductive-aged women with endometriosis. J. Clin. Endocrinol. Metab. 69:837-842.

60. Polan, M. L., A. Daniele, and A. Kuo. 1988. Gonadal steroids modulate human monocyte interleukin-1 (IL-1) activity. Fertil. Steril. 49:964.

61. Polan, M. L., J. Loukides, P. Nelson, S. Carding, M. Diamond, A. Walsh and $\mathrm{K}$. Bottomly. 1989. Progesterone and estradiol modulate interleukin- $1 \beta$ messenger ribonucleic acid levels in cultured human peripheral monocytes. J. Clin. Endocrinol. Metab. 69:1200-1206.

62. Bonucci, E. 1974. The organic-inorganic relationships in bone matrix undergoing osteoclastic resorption. Calcif. Tiss. Res. 16:13-36.

63. Robey, G. H., L. W. F. Shen, M. F. Young, and J. D. Termine. 1988. The biochemistry of bone. In Osteoporosis: Etiology, Diagnosis, and Management. B. L. Riggs and L. J. Melton III, editors. Raven Press, New York. 95-109.

64. Dinarello, C. L., T. Ikejima, S. J. C. Warner, S. F. Orencole, G. Lonneman, J. G. Cannon, and P. Libby. 1987. Interleukin-1 induces interleukin-1. I Induction of circulating interleukin-1 in rabbits in vivo and in human mononuclear cells in vitro. J. Immunol. 139:1902.

65. Polla, B. S., A. M. Healy, M. Byrne, and S. M. Krane. 1987. 1,25-Dihydroxyvitamin $\mathrm{D}_{3}$ induces collagen binding to the human monocyte line U937. $J$. Clin. Invest. 80:962-969. 